\title{
Stigma Toward HIVIAIDS People
}

\author{
M.Sc. Violeta Zefi \\ University of Prishtina \\ E-mail: violetazefi@gmail.com
}

\section{Doi:10.5901/mjss.2013.v4n2p411}

\begin{abstract}
:
The primary goal of this research was to examine attitudes towards people living with HIVIAIDS, namely the level of stigma towards these people. Another goal of this research was to examine the knowledge about HIVIAIDS and the perceived risk of infection with HIV, as well as analysing their relation with stigmatisation. Given that the research seeks to measure students' knowledge and attitudes towards people living with HIVIAIDS and their perception of risk of HIVIAIDS, the research method used is the quantitative one, with questionnaire. The survey study was conducted with 200 students from various departments of the University of Prishtina. Knowledge about HIVIAIDS among students was not complete, i.e. they have misconceptions regarding the ways of transmission of HIV virus. There exists stigma against people living with HIVIAIDS. The average stigma within the Department of Psychology has been: $X=34.9, X=$ 34.3 within the Faculty of Medicine, $X=36.9$ within the Department of Chemistry and the average of stigma within the Faculty of Electrical Engineering and Computer have been $X=37.7$. The less that students were informed on HIVIAIDS, the higher was their level of stigma. Perception of risk to HIVIAIDS was very low.
\end{abstract}

Keywords: HIVIAIDS; stigma; knowledge; attitude; risk perception, youths.

\section{Introduction}

AIDS (Acquired Immunodeficiency Syndrome) is an infectious disease caused by the Human Immunodeficiency Virus HIV (Fieldhouse \& Alcorn, 2007). Nowadays, AIDS is considered as one of the most dangerous and incurable diseases of the modern society. The disease was first confirmed in 1981 in the USA, while it was for the first time reported by the American doctor Michael Godleed (Fieldhouse and Alcorn, 2007).

AIDS as a worldwide pandemic is increasingly being spread in Kosovo. According to the classification system of the United Nations HIVIAIDS Joint Programme (UNAIDS), Kosovo is characterized by a low number of people with HIVIAIDS (Kosovo HIVIAIDS Committee, 2004 - 2008). However, Kosovo is located in the region of Southeast Europe, which is recognized as one of the regions with the fastest speed of spreading of the HIV epidemic in the world. The situation regarding sexually transmitted diseases (STDs) and HIVIAIDS in Kosovo is unclear due to lack of reporting, of accurate information and of insufficient prevention programmes. The increase of risk factors faced by people in Kosovo, including changes in economic and social situation, suggest the need for strengthening surveillance, prevention and efforts to control HIV and STDs (Kosovo HIVIAIDS Committee, 2004 - 2008).

Although the prevalence of HIV is low, Kosovo has specific elements that may lead to increase of the scale of epidemic, if not prevented at early stages. As an economically underdeveloped country, with the highest unemployment rate in the Balkans and with few opportunities for development in many aspects, young people aged 18-25 years increasingly face particular challenges that can lead to increased exposure and susceptibility to HIV.

Kosovo possesses identifiable factors that put people at risk for infection, such as a very young population, high unemployment, rapid social changes within the family and society, the growing problem of narcotics industry, booming of sex industry, a stigmatized homosexual community, high rate of population migration, both within and outside Kosovo, and a community with a fairly large number of internationals (both from countries with high prevalence of HIVIAIDS and from those with different customs and cultures).

Kosovo's youngsters face a world that is undergoing rapid change. Social changes have a direct impact on their attitudes and behaviour, particularly in the sphere of sexual behaviour and drug use. Studies in Kosovo have shown that the age of sexual debut is declining rapidly among young people, as well as beginning of drug use. High level of 
unemployment, especially among young people, has resulted in labour migration to Western European countries. Unemployed young people mainly travel abroad on their own and without their partners, which increases their vulnerability to HIV infection. Their limited knowledge and awareness on HIV and other sexually transmitted diseases are major risk factors.

\subsection{Stigmatisation of people living with HIVIAIDS in the world and in Kosovo}

Particular cultures or communities stigmatize certain behaviours in different ways. Most widespread forms of stigma include: physical and social isolation, judgment or blaming people, denial of rights, etc. (Catalan, 2003). Cases of stigma against people with HIVIAIDS are found throughout the world since the early diagnosis of this disease. This stigma often targets individuals, families, groups and communities who people living with HIVIAIDS associate with (Catalan, 2003).

Stigma is a frequent reaction to various diseases. Throughout history, many diseases have brought stigma, including: tuberculosis, cancer, mental illnesses and many different sexually transmitted infections (Catalan, 2003).

There are different definitions of stigma. According to UNAIDS guidelines, 'stigma' is 'a shameful sign or trace, or impairment of the individual' (UNAIDS, 2008). Stigma is a type of prejudice that discredits or rejects an individual or a group because he or they differ from others or from ordinary people (Herek \& Capitanio, 1999). Stigma has deep roots in the structure of society as a whole and in the norms deriving from the daily life of every society. As such, stigmatization is generally intended to discredit and shame certain groups (Herek \& Capitanio, 1999).

Goffman (2007), who is recognized as among the first who has investigated the concept of stigmatisation, defines it, in general terms, as an undesirable and shaming quality of the individual, thus diminishing the status of that individual in the eyes of the society (Visser, 2007, p. 1). Stigma can be a result of specific features, such as physical deformities, for instance visible symptoms of disease, or can come from negative attitudes towards the behaviour of certain groups, such as homosexuals, drug users, commercial sex workers etc. (Visser, 2007). Similarly, Herek and Mitnick (2007) define the stigma associated with AIDS as prejudice, disgrace and discrimination directed people living with HIVIAIDS and toward individuals, groups and communities with whom they associate (Visser, 2007, p. 1).

Manifestation of stigma refers to the form, type and way in which stigma is known, identified and projected. There are two basic forms of manifestation of stigma: (1) institutionalized stigma and (2) individual stigma (Guni, 2005). Institutionalized stigma is the situation when an institution - such as hospitals or other institutions dealing with various forms of healthcare - practices stigmatization, be it actively or passively. On the other hand, individualized stigma is the situation when attitudes are directed toward an individual. Individualized stigma is doubled in that it can be done by a person or a group of persons directed to an individual and based upon negative social attitudes and perceptions (Guni, 2005).

HIV diagnosis increases the tension and psycho-social vulnerability of people living with HIVIAIDS (Babayan et al., 2007). HIV diagnosis is a psycho-traumatic situation that brings psycho-emotional reactions such as shock, sadness, suicidal thoughts, fear, loss, grief, feeling of guilt, depression, low self-esteem, etc. (Babayan et al., 2007). When people realize they are infected with HIV, their reactions tend to follow a series of stages - stages of the reaction to the HIV positive status - although these stages are not fixed (Ross, Danawi, Mizwa, Cogan, Klein, Magongo, and Kganakga, 2005). According to Ross et al., (2005) these reaction stages are the following:

- The first stage is shock, denial, and anger. People can feel guilty about their infection, or angry at those they believe they were infected by.

- The second stage is withdrawal: they face the stigma associated with HIVIAIDS and worry about how others will react to their condition.

- The third stage is characterized by care for others to tell about their HIV status.

- In the fourth stage, people can look for others who are in the same situation to receive support and discuss the same problems they faced.

- In some instances, in a fifth stage the persons infected can view themselves as special or different. This behaviour - occasionally - is followed by an altruistic behaviour or acceptance of their status as infected (Ross et al., 2005).

Research conducted so far show that there is a high degree of stigma towards people living with HIVIAIDS in Kosovo. The research 'Knowledge, Attitude and Habits of Youngsters to Sexual and Reproductive Health' (National Public Health Institute, 2001) showed that among young Kosovars aged $14-19$, knowledge of sexually transmitted infections and HIVIAIDS are insufficient and that HIV positive people are highly stigmatized (National Public Health Institute, 2001). According to the survey, in $43.7 \%$ of respondents' families they never talk about intimate topics and 
issues of sexual and reproductive health. Such a type of conversation is considered a shame in these families (National Public Health Institute, 2001).

Moreover, the research 'Knowledge of School Youth on AIDS' (Ministry of Health, 2001) has shown that there are many prejudices among students about people living with HIVIAIDS (Ministry of Health, 2001). Based on the findings of this survey, most students prefer to distance themselves from their peers living with HIVIAIDS from the society and think that these people should be treated in special institutions and separated from the rest of people. Results of this research have also shown that although more than $90 \%$ of students know that HIV is not transmitted through the use of shared toilets, only $10 \%$ of them would have used the same toilet as that used by a person infected with HIV (Ministry of Health, 2001).

People living with HIVIAIDS are usually blamed by family, friends and community for their condition, especially if they are infected with HIV through sexual intercourse or through drug injection (Herek \& Capitanio, 1999). This observation is also confirmed by the research 'Knowledge, Attitudes, Practices and Behaviour of Young People in Kosovo on HIVIAIDS' (National Public Health Institute, 2004), where HIV is described as 'a disease of shame' gained through unrestrained sex, drug addiction and by homosexuals (National Public Health Institute, 2004).

People living with HIVIAIDS face various problems. This was also shown by the research 'Assessing PsychoSocial-Medical Needs of Persons with HIVIAIDS and Their Involvement in Awareness Programmes' (National Centre for Community Services, 2008), carried out in Albania, which has proven that the main problems facing persons living with HIVIAIDS are: non-access to services necessary for treatment, fear of death, fear of contempt, fear that they will remain alone etc. (National Centre for Community Services, 2008).

Furthermore, research on 'Behavioural and Biological Aspects of HIV and Sexually Transmitted Diseases' (United Nations Kosovo Team - UNKT, 2006) in Kosovo has shown that people living with HIVIAIDS and those affected by HIVIAIDS are highly stigmatized by society (United Nations Kosovo Team, 2006). Due to the fear of rejection by family, friends or community, the majority of HIV positive people do not disclose their condition even to their friends or close families (UNKT, 2006).

Compared to the early post-war years in Kosovo, the level of information on HIVIAIDS among young people has increased (United Nation Kosovo Team, 2008). The research on 'Knowledge, Attitudes, Practices and Behaviour of Young People in Kosovo in Relation to HIVIAIDS' (United Nation Kosovo Team, 2008) has found that young people are highly informed about HIVIAIDS; $90 \%$ of them have heard about HIVIAIDS. However, less than half (47\%) of them are aware of the difference between these two expressions: HIV and AIDS. The same research has concluded that AIDS is a taboo subject as it is related to sex. There also dominates a strong bias among the general public on the nature of this disease, which is described as 'a shameful disease' gained from unrestrained sex, drug addiction, by homosexuals and people who do not care enough about personal hygiene (UNKT, 2008).

Results of the research on 'Knowledge, Attitudes and Behaviour of Healthcare Workers in Relation to HIVIAIDS' (National Public Health Institute, 2004) have shown that there are prejudices among Kosovar healthcare workers towards people living with HIVIAIDS and lack of knowledge on HIVIAIDS. This research has also found that $48 \%$ of respondents would not isolate a person living with HIV, while $43 \%$ would isolate a person living with HIV, and $9 \%$ did not know how they would go about with a patient infected with HIV (National Public Health Institute, 2004). Consequently, what is more worrying is the stigma that occurs in healthcare institutions. Stigma and discrimination in healthcare centres are caused by several factors: lack of knowledge among healthcare staff on ways and risks of HIV transmission; judgmental attitudes towards behaviour of people living with HIVIAIDS; fear of infection in the work place, etc. (Partnerships in Health, 2008).

Consequences of stigma and discrimination associated with HIVIAIDS are spread beyond to only people living with HIVIAIDS. People who do not know their HIV status are potential targets of stigmatization and discrimination (Partnerships in Health, 2008). Due to the fear of being stigmatized, they are afraid to do the test and live in anxiety without knowing their HIV condition and at the same time can spread infection to other persons. Stigma also prevents people to talk and be informed about HIV as a major cause of illness and death. Stigma prevents people infected with HIV from seeking advice, receiving proper health and psychosocial care, and taking prevention measures to avoid infecting others (Partnerships in Health, 2008)

\section{Methodology}

\subsection{Sample}

This research has been conducted using the survey method, which included selection of students who underwent the 
survey through a self-administered questionnaire. The survey includes two hundred (200) participants. The average age was $X=19.8$, the minimum age being 18 and the maximum one 35. Participants came from 14 municipalities of Kosovo. Out of the overall sample, 112 participants (59 males and 53 females) were permanent urban residents, while 88 participants (44 males and 44 females) were permanent rural residents. Of all participants, only 12 of them were married, while 188 were unmarried. In terms of employment status, 42 of the participants were employed, while the rest, namely 115 participants, were unemployed. 21 participants from the overall sample stated that they were looking for a job, while 22 of them were not looking for a job.

Table 1. Socio-demographic data of participants

\begin{tabular}{|l|c|c|c|c|}
\hline & Average $(\mathrm{X})$ & Stand. D. $(\mathrm{SD})$ & MIN. & MAX. \\
\hline Age & 19.8 & 1.8 & 18.0 & 35.0 \\
\hline Gender & 1.4 & 0.5 & 1 & 2 \\
\hline Permanent residence & 1.4 & 0.4 & 1 & 2 \\
\hline Municipality & 6.7 & 4.1 & 1 & 14 \\
\hline Study branch & 2.5 & 1.1 & 1 & 4 \\
\hline Year of studies & 1.1 & 0.3 & 1 & 2 \\
\hline Marital status & 1.0 & 0.2 & 1 & 2 \\
\hline Employment status & 2.1 & 0.8 & 1 & 4 \\
\hline
\end{tabular}

The sample was structured with 50 participants from each branch of studies, while the participants were selected randomly. Participation in the survey was voluntary. The sample included participants of four branches of studies at the University of Prishtina: Department of Psychology, Faculty of Medicine, Department of Chemistry and Faculty of Electrical and Computer Engineering.

\subsection{Instrument}

Given that the research aims to measure students' knowledge and attitudes towards people living with HIVIAIDS, as well as perception of risk to HIVIAIDS, the quantitative method, using a questionnaire, was considered to be more appropriate and suitable. As stated above, the questionnaire was used for the empirical part of the research.

The questionnaire was anonymous. The demographic data requested are the following: age, gender, permanent residence, Municipality, branch of studies, marital status, and employment status. The questionnaire contained 30 questions in total. In addition to demographic data, the questionnaire contained three sections of questions.

The first section of the questionnaire contained questions about students' knowledge about HIV/AIDS. It included 11 questions, using the Likert scale as a measuring tool, namely a scale from 1 to 4 , except 3 questions, which had 5, 7, respectively 8 maximum points, and one question using 'Yes' and 'No' response options. The second section of the questionnaire contained questions about students' attitudes towards people living with HIVIAIDS. It included 16 questions in total, using the Likert scale as a measuring tool, namely a scale from 1 to 4 , except one question using 'Yes' and 'No' response options. Lastly, the third section of the questionnaire contained three questions aimed at determining perception of the risk of becoming infected with HIV, also using the Likert scale as a measuring tool, namely a scale from 1 to 4,6 and 7 , respectively.

\subsection{Procedure}

The questionnaire was filled out in the premises of the respective faculties (Psychology, Medicine, Chemistry, and Electrical and Computer Engineering) and respondents participated voluntarily. It took an average of $10-15$ minutes to complete one questionnaire. Participants were given clear instructions for filling in the questionnaire. It was also made sure that the questionnaire be filled in individually, in order to protect anonymity and confidentiality of the data. The entire period of filling in of the questionnaire lasted 4 days and was followed by data analysis. 
An informing permission for conducting the research was obtained, with participants informed in advance about the research and its purpose. Confidentiality was guaranteed through data storage and by informing the respondents that the data will be used only for the purposes of this research.

\section{Results}

3.1. Impact of constant (demographic) variables on the knowledge about HIV/AIDS, stigma and risk perception from HIVIAIDS

Analysis of relations between gender and the level of knowledge does not show a significant correlation $[r(2,199)=2.33$, $p=0.128]$. The average level of knowledge among men was $X=23.0$ and $D S=3.3$, while the average knowledge among women was $X=23.6$ and DS $=3.0$ (see Table 2.). Although women have slightly more knowledge than men, differences are not significant, and therefore one cannot claim that gender affects knowledge on HIVIAIDS.

Table 2: Impact of gender on the level of knowledge

\begin{tabular}{|c|c|c|}
\hline Gender & Mean $(\mathrm{X})$ & Standard Deviation (SD) \\
\hline Male & 23.0 & 3.3 \\
\hline Female & 23.6 & 3.0 \\
\hline
\end{tabular}

Furthermore, in terms of the correlation between the field of study and level of knowledge, the following results were found: average knowledge in the Department of Psychology was $X=24.2$ and DS $=2.2$; average knowledge in the Faculty of Medicine was $X=24.3$ DS $=3.1$; average knowledge in the Department of Chemistry was $X=22.4$ and DS = 3.2, and average knowledge in the Faculty of Electrical Engineering and Computer was $X=22.3$ and DS $=3.0$ (see Table 3.). Differences are significant $[r(4,199)=6.72, p=0.000]$. This shows that the field of study has a significant correlation with the level of knowledge about HIVIAIDS. We can say that the field of study has in impact on the level of knowledge: students of psychology and medicine have a higher level of knowledge compared to those of the Department of Chemistry and Faculty of Electrical Engineering and Computer.

Table 3: Influence of study field on the level of knowledge

\begin{tabular}{|l|c|c|}
\hline Field of study & Mean $(\mathrm{X})$ & Standard Deviation (SD) \\
\hline Department of Psychology & 24.2 & 2.2 \\
\hline Faculty of Medicine & 24.3 & 3.1 \\
\hline Department of Chemistry & 22.4 & 3.2 \\
\hline $\begin{array}{l}\text { Faculty of Electrical } \\
\text { Engineering and Computer }\end{array}$ & 22.3 & 3.0 \\
\hline
\end{tabular}

Concerning the correlation between area of residence and the level of knowledge, the following results were found: average knowledge in urban areas was: $X=23.6$ and $D S=3.4$ and the average knowledge in rural areas was $X=22.8$ and DS $=2.8$ (see Table 4.). Therefore, differences are not significant $[r(2,199)=3.11, p=0.079]$. This shows that there is no significant correlation between the area of permanent residence and the level of knowledge on HIVIAIDS.

Table 4: Impact of permanent residence on the level of knowledge

\begin{tabular}{|l|c|c|}
\hline Permanent Residence & Mean $(\mathrm{X})$ & Standard Deviation (SD) \\
\hline Urban & 23.6 & 3.4 \\
\hline Rural & 22.8 & 2.8 \\
\hline
\end{tabular}


Analysis on the relation between gender and the level of stigma show a significant correlation $[r(2,200)=13.4, p=$ 0.000 ]. Average stigma among men was 36.9 and $X=D S=4.1$, while the average stigma among women was $X=34.9$ and $\mathrm{DS}=3.6$ (see Table 5.). This shows that women have a lower level of stigma compared to men.

Table 5: Impact of gender on the level of stigma

\begin{tabular}{|l|c|c|}
\hline Gender & Mean $(\mathrm{X})$ & Standard Deviation $(\mathrm{SD})$ \\
\hline Male & 36.9 & 4.1 \\
\hline Female & 34.9 & 3.6 \\
\hline
\end{tabular}

Regarding the correlation between the field of study and the level of stigma, the following results have been found: the average level of stigma in the Department of Psychology was $X=34.9$ and $D S=3.9$; average stigma in the Faculty of Medicine $X=34.3$ and $D S=3.7$; average stigma in the Department of Chemistry was $X=36.9$ and $D S=3.9$, and the average stigma in the Faculty of Electrical Engineering and Computer was $X=37.7$ and $D S=3.6$ (see Table 6.)., while differences are significant $[r(4,198)=8.86, p=0.000]$. This study shows that the field of studies has a significant correlation to the level of stigma.

Table 6: Impact of field of study on the level of stigma

\begin{tabular}{|l|c|c|}
\hline Field of study & Mean $(\mathrm{X})$ & Standard Deviation (SD) \\
\hline Department of Psychology & 34.9 & 3.9 \\
\hline Faculty of Medicine & 34.3 & 3.7 \\
\hline Department of Chemistry & 36.9 & 3.9 \\
\hline Faculty of Electrical Engineering and Computer & 37.7 & 3.6 \\
\hline
\end{tabular}

Regarding the correlation between area of permanent residence and the level of stigma, the following results have been found: the average of stigma in urban areas was: $X=36.0$ and $D S=4.3$, and the average stigma in rural areas was: $X=35.8$ and $D S=3.6$, differences not being significant [r $(2,198)=0.14, p=0.705]$, (see Table 7.). This indicates that there is no significant correlation between area of residence and the level of stigma.

Table 7: Impact of permanent residence on the level of stigma

\begin{tabular}{|l|c|c|}
\hline Permanent Residence & Mean $(\mathrm{X})$ & Standard Deviation (SD) \\
\hline Urban & 36.0 & 4.3 \\
\hline Rural & 35.8 & 3.6 \\
\hline
\end{tabular}

Analyses on the correlation between gender and risk perception do not show a significant correlation $[r(2,199)=$ $0.975, p=0.325]$. The average risk perception for men was $X=9.5$ and $D S=2.6$, while the average risk perception for women was $X=9.1$ and $D S=2.8$ (see Table 8.). This shows that there is no correlation between gender and perception of risk.

Table 8: Impact of gender on the risk perception

\begin{tabular}{|l|c|c|}
\hline Gender & Mean $(\mathrm{X})$ & Standard Deviation (SD) \\
\hline Male & 9.5 & 2.6 \\
\hline Female & 9.1 & 2.8 \\
\hline
\end{tabular}

In terms of correlation between field of studies and risk perception, the following results have been found: average risk perception in the Department of Psychology was $X=9.0$ and $D S=2.4$; average risk perception in the Faculty of Medicine was $X=9.8$ and DS $=2.7$; average risk perception in the Department of Chemistry was $X=9.2$ and $D S=2.7$, 
and average risk perception in the Faculty of Electrical Engineering and Computer was $X=9.4$ and DS $=3.1$, while differences are not significant $[r(4,199)=0.775, p=0.509]$, (see Table 9.). This shows that there is no significant correlation between the area of studies and risk perception from HIVIAIDS.

Table 9: The impact of study on the risk perception

\begin{tabular}{|l|c|c|}
\hline Field of study & Mean $(X)$ & Standard Deviation (SD) \\
\hline Department of Psychology & 9.0 & 2.4 \\
\hline Faculty of Medicine & 9.8 & 2.7 \\
\hline Department of Chemistry & 9.2 & 2.7 \\
\hline Faculty of Electrical Engineering and Computer & 9.4 & 3.1 \\
\hline
\end{tabular}

Moreover, concerning the correlation between area of permanent residence and perception of risk, the following results have been found: average risk perception in urban residence was: $X=9.3$ and $D S=2.8$, average perception of risk in rural areas was: $X=9.4$ and $D S=2.7$, while the differences are not significant $[r(2,200)=0.69, p=0.793]$ (see Table 10.). This indicates that there is no significant correlation between the area of permanent residence and perception of risk from HIVIAIDS.

Table 10: Impact of area of permanent residence on risk perception

\begin{tabular}{|l|c|c|}
\hline Permanent Residence & Mean $(\mathrm{X})$ & Standard Deviation (SD) \\
\hline Urban & 9.3 & 2.8 \\
\hline Rural & 9.4 & 2.7 \\
\hline
\end{tabular}

3.2 Correlation between knowledge on HIV/AIDS, stigma and perception of risk calculated in constant (demographic) variables

Using the field of studies as a controlling variable, the correlation between knowledge on HIVIAIDS and the level of stigma has resulted as significant, namely a negative correlation, which means that while knowledge about HIVIAIDS increases, the level of stigma decreases [r $(2,200)=-0.303, p=0000]$, (see table 11.).

On the other hand, using field of studies as controlling variable, the positive correlation between knowledge and perception of risk from HIVIAIDS has resulted as significant, which means that with increased knowledge about HIVIAIDS the perception of risk increases $[r(2,200)=0.987, p=0.001]$ (see Table 11.).

Using the field of study as a controlling variable, the correlation between the perception of risk and the level of stigma has not resulted as significant, although it is close to significant $(p=0.069)$, and the positive correlation is 0.130 . This means that increased stigma increases the perception of risk, yet one cannot say that the correlation is significant $[r(2,200)=0.069, p=0.130]$, (see table 11.).

Table 11: Correlation between knowledge on HIVIAIDS, stigma and risk perception, calculated in relation to the field of studies

\begin{tabular}{|c|c|c|c|}
\hline \multicolumn{4}{|l|}{ Correlation } \\
\hline \multicolumn{2}{|l|}{ Controlled Variable: Field of study } & $\begin{array}{c}\text { Knowledge about } \\
\text { HIVIAIDS }\end{array}$ & $\begin{array}{c}\text { Level of } \\
\text { stigmatization }\end{array}$ \\
\hline \multirow{2}{*}{ Level of stigmatization } & Correlation & -.303 & \\
\hline & Significance & .000 & \\
\hline \multirow{2}{*}{ Risk perception } & Correlation & .001 & .130 \\
\hline & Significance & .987 & .069 \\
\hline
\end{tabular}


Using gender as controlling variable, the correlation between knowledge on HIVIAIDS and the level of stigma has resulted in a significant one, namely a negative one, which means that an increased level of knowledge leads to a decreased level of stigma $[r(2,200)=-0.347, p=0.000]$ (see Table 12.).

In addition, using gender as a controlling variable, the correlation between perception of risk and knowledge about HIVIAIDS has not resulted as a significant positive one, which means that with increased knowledge about HIVIAIDS the perception of risk increases $[r(2,200)=0.989, p=0.001]$ (see Table 12.).

Furthermore, using gender as a controlling variable, the correlation between perception of risk from HIVIAIDS and the level of stigma has not resulted as a significant one, and it is a positive one $[r(2,200)=0.119, p=0.096]$, (see table 12.).

Table 12: Correlation between knowledge on HIVIAIDS, stigma and risk perception calculated by gender

\begin{tabular}{|c|c|c|c|}
\hline \multicolumn{4}{|l|}{ Correlation } \\
\hline \multicolumn{2}{|l|}{ Controlled Variable: Gender } & $\begin{array}{c}\text { Knowledge about } \\
\text { HIVIAIDS }\end{array}$ & Level of stigmatization \\
\hline \multirow{2}{*}{$\begin{array}{l}\text { Knowledge about } \\
\text { HIVIAIDS }\end{array}$} & Correlation & & -.347 \\
\hline & Significance & & .000 \\
\hline \multirow{2}{*}{ Risk perception } & Correlation & .001 & .119 \\
\hline & Significance & .989 & .096 \\
\hline
\end{tabular}

Using area of permanent residence as controlling variable, the correlation between knowledge on HIVIAIDS and the level of stigma has resulted as significant one, and it is negative, which means an increased knowledge on HIVIAIDS leads to decreased level of stigma $[r(2,200)=-0.366, p=0000]$, (see table 13.).

Furthermore, using area of permanent residence controlling variable, the correlation between perception of risk and knowledge on HIVIAIDS has not resulted as significant and it is a positive one, which means with the increase of knowledge on HIV/AIDS the perception of risk increases [r $(2,200)=0.954, p=0.004]$, (see table 13.).

Using the area of permanent residence as a controlling variable, the correlation between perception of risk and the level of stigma have not resulted as a significant $(p=0.064)$ and it is a positive one (0132), which means that an increased level of stigma increases the level of perception of risk [ $r(2,200)=-0.132, p=0.064]$, (see table 13.).

Table 13: Correlation between knowledge on HIVIAIDS, stigma and risk perception calculated with area of permanent residence

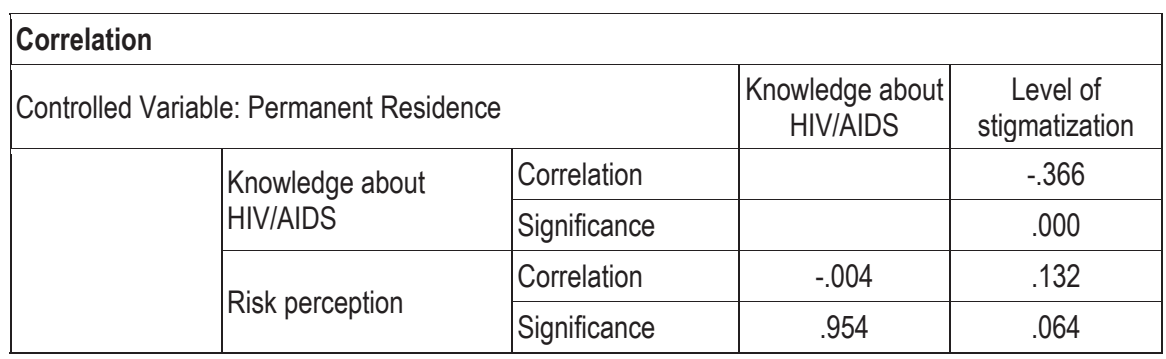

\subsection{Regression of knowledge on HIV/AIDS, stigma and risk perception, calculated with constant (demographic) variables}

Linear regression, entering the variables one by one, was performed by using the 'knowledge about HIVIAIDS' variable, as the dependent one. Results showed that the Department of Psychology and the Faculty of Medicine turned out to have significant knowledge, whereas other variables, such as Faculty of Electrical and Computer Engineering, Department of 
Chemistry, Females and Males, Urban and Rural Residence, turned out as not having significant knowledge (see Table 14).

Partial correlation of the Department of Electrical and Computer Engineering and Rural Residence in terms of knowledge on HIVIAIDS has resulted to be a negative one, while other variables, such as: Department of Psychology and Chemistry, Faculty of Medicine, Women, Men and Urban Residence, have positive correlation (see Table 14).

Table 14. Regression of knowledge on HIVIAIDS, calculated through demographic variables

\begin{tabular}{|c|c|c|c|c|}
\hline \multicolumn{5}{|c|}{ Coefficients $^{\mathrm{a}}$} \\
\hline \multicolumn{2}{|c|}{ Model } & \multirow{2}{*}{$\begin{array}{c}\begin{array}{c}\text { Standardized } \\
\text { Coefficients }\end{array} \\
\text { Beta } \\
\end{array}$} & \multirow{2}{*}{ Significance } & \multirow{2}{*}{$\begin{array}{c}\text { Partial } \\
\text { Correlation }\end{array}$} \\
\hline & & & & \\
\hline \multirow{2}{*}{1} & (Constant) & & & \\
\hline & Psychology & .171 & .016 & .171 \\
\hline \multirow{2}{*}{2} & (Constant) & & & \\
\hline & Medicine & .268 & .000 & .257 \\
\hline \multirow{2}{*}{3} & (Constant) & & & \\
\hline & Chemistry & .016 & .845 & .014 \\
\hline \multirow{2}{*}{4} & (Constant) & & & \\
\hline & Electrical and Computer Engineering & -.049 & .733 & -.025 \\
\hline \multirow{2}{*}{5} & (Constant) & & & \\
\hline & Female & .030 & .698 & .028 \\
\hline \multirow{2}{*}{6} & (Constant) & & & \\
\hline & Male & .108 & .119 & .112 \\
\hline \multirow{2}{*}{7} & (Constant) & & & \\
\hline & Urban & .111 & .107 & .116 \\
\hline \multirow{2}{*}{8} & (Constant) & & & \\
\hline & Rural & -.543 & .293 & -.076 \\
\hline
\end{tabular}

Linear regression, entering the variables one by one, was performed by using the level of stigmatization as a dependent variable. Results showed that the Department of Psychology, Faculty of Medicine, Faculty of Electrical and Computer Engineering and females were significant, whereas other variables, such as Faculty of Chemistry, males, urban and rural residence, resulted as not significant (see Table 15). Partial correlation of the Department of Psychology, Faculty of Medicine, the Department of Chemistry, Department of Electrical and Computer Engineering and females in relation to the level of stigmatization on HIVIAIDS is negative, while other variables, such as male, urban and rural residence, have positive correlation (see Table 15).

Table 15. Regression of the level of stigmatization, calculated through demographic variables

\begin{tabular}{|l|l|c|c|c|}
\hline \multicolumn{2}{|l|}{ Coefficientsa } \\
\hline \multirow{2}{*}{ Model } & $\begin{array}{c}\text { Standardized } \\
\text { Coefficients }\end{array}$ & \multirow{2}{*}{ Significance } & \\
\cline { 3 - 3 } \cline { 5 - 5 } & Beta & & Partial correlation \\
\hline \multirow{2}{*}{1} & (Constant) & & & -.147 \\
\cline { 2 - 5 } & Psychology & -.147 & .039 & \\
\hline 2 & (Constant) & & & \\
\hline
\end{tabular}




\begin{tabular}{|c|c|c|c|c|}
\hline & Medicine & -.324 & .000 & -.309 \\
\hline \multirow{2}{*}{3} & (Constant) & & & \\
\hline & Chemistry & -.086 & .297 & -.075 \\
\hline \multirow{2}{*}{4} & (Constant) & & & \\
\hline & Electrical and Computer Engineering & -.358 & .011 & -.182 \\
\hline \multirow{2}{*}{5} & (Constant) & & & \\
\hline & Female & -.172 & .019 & -.167 \\
\hline \multirow{2}{*}{6} & (Constant) & & & \\
\hline & Male & .034 & .604 & .037 \\
\hline \multirow{2}{*}{7} & (Constant) & & & \\
\hline & Urban & .035 & .605 & .038 \\
\hline \multirow{2}{*}{8} & (Constant) & & & \\
\hline & Rural & .118 & .814 & .017 \\
\hline
\end{tabular}

Linear regression, entering the variables one by one, was performed by using the perception of risk as a dependent variable. Results showed that none of the variables were significant (see Table 16). Partial correlation of the Department of Psychology, Faculty of Chemistry, females, males and urban residence in relation to the perception of risk to HIVIAIDS is negative, while other variables, such as male, urban and rural residence, have positive correlation (see Table 16).

Table 16. Regression of risk perception, calculated through demographic variables

\begin{tabular}{|c|c|c|c|c|}
\hline \multicolumn{5}{|c|}{ Coefficients $^{\mathrm{a}}$} \\
\hline \multirow{2}{*}{\multicolumn{2}{|c|}{ Model }} & $\begin{array}{c}\text { Standardized } \\
\text { Coefficients }\end{array}$ & \multirow{3}{*}{ Significance } & \multirow{3}{*}{ Partial correlation } \\
\hline & & \multirow{2}{*}{ Beta } & & \\
\hline \multirow{2}{*}{1} & (Constant) & & & \\
\hline & Psychology & -.076 & .283 & -.076 \\
\hline \multirow{2}{*}{2} & (Constant) & & & \\
\hline & Medicine & .074 & .329 & .070 \\
\hline \multirow{2}{*}{3} & (Constant) & & & \\
\hline & Chemistry & -.041 & .640 & -.033 \\
\hline \multirow{2}{*}{4} & (Constant) & & & \\
\hline & Electrical and Computer Engineering & .076 & .610 & .037 \\
\hline \multirow{2}{*}{5} & (Constant) & & & \\
\hline & Female & -.063 & .428 & -.057 \\
\hline \multirow{2}{*}{6} & (Constant) & & & \\
\hline & Male & -.026 & .719 & -.026 \\
\hline \multirow{2}{*}{7} & (Constant) & & & \\
\hline & Urban & -.024 & .742 & -.024 \\
\hline \multirow{2}{*}{8} & (Constant) & & & \\
\hline & Rural & .317 & .561 & .042 \\
\hline
\end{tabular}




\section{Discussion}

The results of this research proved the first hypothesis, namely that students who have a lack of accurate information about how HIV is transmitted have more stigmatizing attitudes towards people with HIVIAIDS than students who are accurately informed about ways of transmission of HIV.

These results also proved the second hypothesis, namely that students of the Faculty of Medicine and those of the Department of Psychology have lower levels of stigma towards people with HIVIAIDS than students of the Faculty of Chemistry and those of the Faculty of Electrical and Computer Engineering.

Results of this research proved the third hypothesis, namely those students who believe that HIVIAIDS is related to groups such as homosexuals, commercial sex workers and drug users have with more stigmatizing attitudes towards HIV positive persons than students who believe that HIVIAIDS can affect any person regardless of particular social group they belong to.

Results of this study indicate the persistence of uncertainty and misunderstanding about the ways of transmission of HIV. It is certain that a great extent of spreading of misunderstanding about possible ways of transmission of HIV leads to unfounded fear, which limits joint and daily activities with people living with HIV, and encourages social isolation of these people. Moreover, misconceptions about HIV transmission may urge stigmatization and discrimination against people living with HIVIAIDS.

Results of this study have shown that women have a little more knowledge than men, yet differences are not significant, therefore we cannot say that gender influences knowledge about HIVIAIDS. This is also supported by UNKT (2008), which has not shown significant gender-based differences in relation to knowledge about HIVIAIDS. This research has targeted young people aged 15 to 24 . These results are also supported by Leili, Elham and Farkhondeh (2008), which have not shown significant gender-based differences in relation to knowledge about HIVIAIDS. However, the study by Mitra, Sethi, Jana, and Bhattacharya (2003) has shown that there are gender-based differences in relation to knowledge about HIVIAIDS. Results have also shown that males have a higher level of knowledge about HIVIAIDS than females.

On the other hand, the branch of studies has a significant correlation with the level of knowledge about HIVIAIDS. Thus, the branch of studies (Psychology, Medicine, Chemistry, and Electrical and Computer Engineering) affects the level of knowledge about HIVIAIDS. Students of the Department of Psychology and of the Faculty of Medicine have a higher level of knowledge about HIVIAIDS compared to the two other branches - Chemistry and Electrical and Computer Engineering.

Meanwhile, it can be concluded from the research that permanent residence has no significant correlation with the level knowledge about HIVIAIDS. Thus, unlike gender and permanent residence as independent variables, only the branch of studies has significant correlation with the level of knowledge about HIVIAIDS.

Analysis on the correlation between gender and the level of stigma has shown that women have lower level of stigmatization than men. This is also supported by authors Lee, Campbell, and Mulford (1987) and Heaven, Connors, and Kellehear (1990), which has shown significant differences in gender in relation to the level of stigma on HIVIAIDS; namely that women have a lower level of stigma than men. The study by Lee et al (1987), conducted in the U.S., has researched trends of rap towards people living with HIVIAIDS among college students. On the other hand, Paruk, Mohamed, Patel, and Ramgoon (2006) showed opposite results, which have not shown gender-based differences in relation to the level of stigma towards HIVIAIDS. Such incompatible results may resulted due to the small sample (75) used Paruk et al (2006), then socio-cultural differences affecting gender-based differences in terms of attitudes towards persons living with HIVIAIDS, namely the level of stigma against them. Even the study by Leili et al (2008) has not shown gender-based differences in relation to the level of stigma towards HIVIAIDS. Socio cultural differences may be due to gender differences.

Regarding correlation between branch of studies and the level of stigmatization, the results have shown that the branch of studies has significant correlation with the level of stigma. The level of stigmatization was lower among students of the Psychology and Medicine compared to those of Chemistry and Electrical and Computer Engineering.

On the other hand, in terms of correlation between permanent residence and the level of stigma, the results have shown that there is no significant correlation between permanent residence and the level of stigma. Therefore, out of independent variables, only gender and branch of studies, as opposed to permanent residence, has a significant correlation with the level of stigma.

Analysis on the correlation between gender and risk perception did not show a significant correlation. A correlation between gender and perception of risk was shown in the studies of Anderson, Beutel and Maughan (2007), with women 
showing a higher level of risk perception than men. The study conducted in South Africa showed that there may be gender-based differences, due to the large number of cases of HIVIAIDS in Africa, especially the large number of women and children infected.

Results have shown that the branch of studies and permanent residence do not have a significant correlation with risk perception, namely that none of the independent variables (gender, branch of studies and permanent residence) have significant correlation with risk perception.

Results have shown that the correlation of between knowledge about HIVIAIDS and stigma turned out to be of a significant level (using the branch of studies as a controlling variable) and is a negative one, which means that the higher the knowledge on HIVIAIDS, the lower the level of stigma. This is also supported by the author Letamo (2001), with the results of the study having shown that the higher the knowledge on HIVIAIDS, the lower is the level of stigma, namely that there were less negative attitudes towards people living with HIVIAIDS. The study by Letamo (2001) aimed to investigate the factors that influenced stigmatization and discrimination among teenagers towards people living with HIVIAIDS in Bostwana. Moreover, the correlation of knowledge on HIVIAIDS to the risk perception has resulted as a significant one, namely a positive correlation, which means that with the increase of knowledge on HIV / AIDS the risk perception is increased. On the other hand, the correlation between the level of risk perception and stigma has not turned out to be significant, and it is a positive one, which means that risk perception is increased with increased stigma.

The correlation between knowledge on HIVIAIDS and the level of stigma has resulted to be significant (using gender as a controlling variable) and is a negative one, which means that the level of stigma diminishes with increase of the level of knowledge. This is supported by Letamo (2001), namely that the higher the knowledge on HIVIAIDS was, the level of stigma decreased, namely that there were less negative attitudes towards people living with HIVIAIDS. Moreover, the correlation of risk perception with knowledge on HIVIAIDS has not resulted to be a significant and positive one, which means that the risk perception increases with increased knowledge on HIVIAIDS. This is also supported by Yeboah (2008), with results having shown that risk perception increases with increased knowledge about HIV/AIDS. The study by Yeboah (2008) examined the relationship between perception of risk from HIVIAIDS and sexual behaviour in the age between 14 and 22 in South Africa. Furthermore, the correlation between perception of risk from HIVIAIDS and the level of stigma has not resulted to be a significant and positive one, which means that risk perception increases with the increase of stigma.

The correlation between knowledge on HIVIAIDS and the level of stigma (using permanent residence as controlling variable) has turned out to be a significant and negative one, which means that the level of stigma decreases with increased knowledge on HIVIAID. Moreover, the correlation between risk perception and knowledge on HIVIAIDS has not resulted to be a significant and positive one, which means that risk perception is increased with increased knowledge on HIVIAIDS. This is supported by Yeboah (2008), with results having shown that the higher the knowledge about HIVIAIDS, the higher the perception of risk from HIVIAIDS, namely that that there were more positive attitudes towards safe sexual behaviour, especially among women. The correlation between risk perception and the level of stigmatization has not resulted to be a significant and positive one, which means that risk perception increases with the increase of the level of stigma.

Linear regression, entering the variables one by one, was performed by using the 'knowledge about HIVIAIDS' variable as a dependent one. Results showed that the Department of Psychology and the Faculty of Medicine were significant, whereas other variables, such as Faculty of Electrical and Computer Engineering, Department of Chemistry, Women and Men, Urban and Rural Residence, turned out to be not significant. Partial correlation of the Department of Electrical and Computer Engineering and Rural Residence with knowledge on HIVIAIDS is a negative one, while other variables, such as Department of Psychology and Chemistry, Faculty of Medicine, Women, Men and Urban Residence, have a positive correlation.

Linear regression, entering the variables one by one, was performed by using the level of stigma as a dependent variable. Results showed that the Department of Psychology and the Faculty of Medicine and that of Electrical and Computer Engineering, and Women, have resulted to be significant, whereas other variables, such as Department of Chemistry, Male, Urban and Rural Residence, resulted as not significant. Partial correlation of the Department of Psychology, Faculty of Medicine, Department of Chemistry, Department of Electrical and Computer Engineering and Women to the level of stigma on HIVIAIDS is a negative one, while other variables, such as Male, Urban and Rural Residence, have positive correlation.

Linear regression, entering the variables one by one, was performed by using risk perception as a dependent variable, with the results having shown that none of the variables resulted as a significant one. Partial correlation of the Department of Psychology, Department of Chemistry, Female, Male, and Urban Residence with perception of risk from 
HIV/AIDS is a negative one, while other variables, such as the Faculty of Medicine, Department of Electrical and Computer Engineering, and Rural Residence, have positive correlation.

\section{Conclusions}

Knowledge about HIVIAIDS among students is incomplete, namely there are misconceptions regarding ways of HIV transmission. Major misconceptions about HIV transmission concern sharing of toilet seats, daily social contacts (handshakes, hugs), feeding from the same plate with a person living with HIV, transmission of HIV from mosquito bites, etc. The less information on HIVIAIDS students have, the higher is the level of stigma. The level of stigma in the study field of Psychology and Medicine is lower compared to branches of Chemistry and Electrical and Computer Engineering. Perception of risk from HIVIAIDS among students is very low.

While Kosovo is a country with a low level of prevalence of HIVIAIDS, yet with evident factors for increasing the number of HIV infections, there is a convincing need for implementing prevention programmes and measures addressing needs of the population, with particular emphasis on vulnerable groups.

Since research has shown that students do not have full knowledge about HIVIAIDS, respectively that there are misconceptions about ways of transmission of HIV; that there is a high level of stigma among them towards people living with HIVIAIDS and that the perception of risk from HIVIAIDS is very low, then recommendations for action lines have been developed in accordance with the results of research. They are aimed at developing prevention programmes which would include activities related mainly to continuing education programmes (within and outside educational institutions, especially through TV programmes and peer education), aimed at increasing knowledge and creating protective behaviour against HIV among young people in Kosovo. Special attention should be devoted to programmes for reducing stigma and discrimination against people living with HIV/AIDS, with a view to inclusion of these people in social life. Since there is very little research on attitudes towards people living with HIVIAIDS in Kosovo, it is recommended that qualitative and quantitative research be conducted in order to study this issue in more depth.

\section{References}

Anderson, K.; Beutel, A. dhe Maughan, B. (2007). HIV risk perceptions and first sexual Intercourse among youth in Cape Town South Africa. International Family Planning Perspectives. Volume 33, Number 3.

Babayan, V.; Arakelyan, A., Hovhannisyan, E., dhe Arzakanyan, V. (2007). Mental halth problems of people living with HIV/AIDS in Armenia. Mental health and HIVIAIDS Armenia expert centre. Armenia.

Catalan, J. (2003). Mental Health and HIV Infection - Psychological and Psychiatric Aspects. Taylor and Francis. University College London.

Coolican, H. (2004). Research Methods and Statistics in Psychology. Fourth Editon. Hodder \& Stoughton.

Fieldhouse, R., Alcorn, K. (2007). HIV \& AIDS reference manual. NAM. London.

Guni, F. (2005). HIVIAIDS Stigma and Discrimination. National Association of People with AIDS (NAPA). USA.

Heaven, P. C. L., Connors, J., Kellehear, A. (1990). Structure and demographic correlates of attitudes toward AIDS sufferers. The Journal of Psychology, 124(3), 245-252.

Herek, G. (1999). AIDS and Stigma. American Behavioral Scientist. University of California. Vol. 42, No. 7.

Herek.; G. dhe Capitanio, J. (1999). AIDS Stigma and Sexual Pejudice.American Behavioral Scientist. University of California. Vol. 42, No. 7.

Lee, M. Y., Campbell, A. R., Mulford, C. L. (1999). Victim-blaming tendency toward people with AIDS among college students. The Journal of Social Psychology, 139(3), 300-308.

Leili, S.; Elham, Sh., dhe Farkhondeh, S. (2008). A Population-based Survey of HIV/AIDS Knowledge and Attitudes in General Public. Pak J Med Sci. Iran.

Letamo, G. (2001). HIV/AIDS-Related Stigma and Discrimination among Adolescents in Bostwana. University of Bostwana. Bostwana.

Mitra, M.; Sethi, S., Jana, S., Bhattacharya, K. (2003). Gender differences in knowledge, attitudes and prevention of HHIV/AIDS/STI among youth in West Bengal, India. Planned parenthood federation of America-International, and Adolescent resource center, child in need institute. India.

Nushi, P. (2002). Psikologjia e Përgjithshme I. Libri Shkollor. Prishtinë.

Paruk, Z.; Mohamed, S., Patel, C., dhe Ramgoon,S. (2006). Compassion or condemnation? South African Muslim students' attitudes to people with HIVIAIDS. Journal of Social Aspects of HIV/AIDS. South Africa.

Patnerships in health. (2008). Trajnimi bazë për HIV dhe AIDS për punonjësit e kujdesit parësor shëndetësor. Patnerships in health. Prishtinë. 
Qendra kombëtare për shërbime komunitare. (2008). Vlerësimi i nevojave psiko-sociale-mjekësorë të personave me HIVIAIDS si dhe përfshirja e tyre në programet e ndërgjegjësimit. Qendra kombëtarepër shërbime komunitare. Tiranë.

Ross, M., Danawi, H., Mizwa, M., Cogan, L., Klein, M., Magongo, R., Kganakga, C. (2005). Psychosocial aspects of HIV/AIDS: Adults. HIV Curriculum for mental health professionals. WHO.

The Joint United Nations Program on HIVIAIDS. (2007). AIDS epidemic update. The Joint United Nations Program on HIVIAIDS. Switzerland.

The Joint United Nations Program on HIVIAIDS. (2008). Terminology Guidelines. The Joint United Nations Program on HIVIAIDS. Switzerland.

United Nations Kosovo Team. (2008). Njohuritë, qëndrimet, praktikat dhe sjellja e të rinjve në Kosovë mbi HIV/AIDS-in.United Nations Kosovo Team. Prishtinë.

Visser, P. (2007). HIV/AIDS and Stigma. AfroAIDSinfo.

Yeboah, E. (2008). Perceptions of HIVIAIDS risk and sexual behaviour among youth in Cape Town, South Africa. The University of Western Ontario. South Africa. 